\title{
Elliptical Sentences in Open File A Cliff Hardy Novel by PeTer CORRIS
}

\author{
Putu Mesia Pertiwi, I Gusti Bagus Wahyu Nugraha Putra, I. B Gde Nova Winarta \\ Mahasaraswati University, Denpasar
}

pertiwimesia@gmail.com, Wahyunugraha1980@yahoo.com, gusdnova@gmail.com

\begin{abstract}
Ellipsis is a branch of syntax that studies about elimination of words to avoid repetition in a sentence. This study concerns the types of elliptical sentence and analyze the constituent structures of sentences in the novel by Peter Corris in title Open File A Cliff Hardy. This study applied the theory proposed by Quirk and Greenbaum (1973) to find out the types of elliptical sentence and the theory from Brown and Miller (1991) to analyze the constituent structure of a sentence. The data were collected by documentation method and analyzed descriptively by means of a qualitative method. The finding shows that there are five types of elliptical sentences of which the most dominant is ellipsis of subject (and auxiliary).
\end{abstract}

Keywords: Elliptical sentence, Sentence structure

\section{INTRODUCTION}

Language is very important in our life; by language we can conduct communication with other people. In this world there are various languages and English being one of them used in almost all countries and it becomes an essential thing. In using this language, we often make repetition of words that we do not even need to include a replacement for a word or expression that has already been said. Ellipsis is a branch of syntax that studies an elimination of repetitive words. An elliptical sentence is a shorter sentence that has been omitted, but maintains the same meaning to reduce word or words to make it more simply. It is important to know that we can learn how to combine repetition of words without changing the meaning. Novel is a kind of written text that employs ellipses.

\section{MATERIALS AND METHOD}

The data source of this study was taken from Novel written by Peter Corris entitled "Open File A Cliff hardy" (year). The data were collected by using documentation method. through reading the novel intensively. Taking a note of the data which is considered to be ellipsis, then they were classified into types of ellipsis which consist of: Ellipsis of subject (and auxiliary), Ellipsis of auxiliary only, Ellipsis of Predicate or Predication, Ellipsis of Whole of Predication, Auxiliary in Predication, Ellipsis of direct object or subject complement, Ellipsis of head of noun phrase and prepositional complement, and Ellipsis of Adverbial. This study used two theories to answer the problem, they are the theory proposed by Quirk and Greenbaum (1973) to answer the problem of what types of elliptical sentence and the theory proposed by Brown and Miller to answer the problem how the constituent structure of the sentence.

\section{RESULTS AND DISCUSSION}

This study found five types of elliptical sentence. They can be seen below:

\begin{tabular}{|l|l|l|l|}
\hline No. & Types of Elliptical Sentence & Quantity & Percentage \\
\hline 1 & Ellipsis of subject (and auxiliary) & 189 & $94,5 \%$ \\
\hline 3 & Ellipsis of predicate or predication & 8 & $4 \%$ \\
\hline 4 & Ellipsis of whole predication & 1 & $0.5 \%$ \\
\hline 5 & Ellipsis of direct object or subject complement & 1 & $0.5 \%$ \\
\hline 6 & $\begin{array}{l}\text { Ellipsis of head of noun phrase and preposition } \\
\text { complement }\end{array}$ & 1 & $0.5 \%$ \\
\hline
\end{tabular}




\begin{tabular}{|l|l|l|l|}
\hline & Total & 200 & $100 \%$ \\
\hline
\end{tabular}

Table 1. Types of Elliptical Sentence

\subsection{ELLIPSIS OF SUbJECT (AND AUXILIARY)}

Ellipsis of subject (and auxiliary) is the subject of sentence is ellipted if the subject is identical. In the Open File A Cliff Hardy by Peter Corris 189 data of ellipsis of subject (and auxiliary) were found. Only one selected example is illustrated below:

Data 1: Hesubbed out the cigarette and Shuffled a pile of papers on his desk

This sentence is categorized as ellipsis of subject (and auxiliary), originally the sentence is $\mathrm{He}$ subbed out the cigarette and (he) shuffled a pile of papers on his desk, however after being omitted the sentence becomes He subbed out the cigarette and Shuffled a pile of papers on his desk. The subject (he) in the second clause is ellipted. Therefore, this sentence can be categorized as ellipsis of subject (and auxiliary. Constituent structure of sentence can be seen as below:

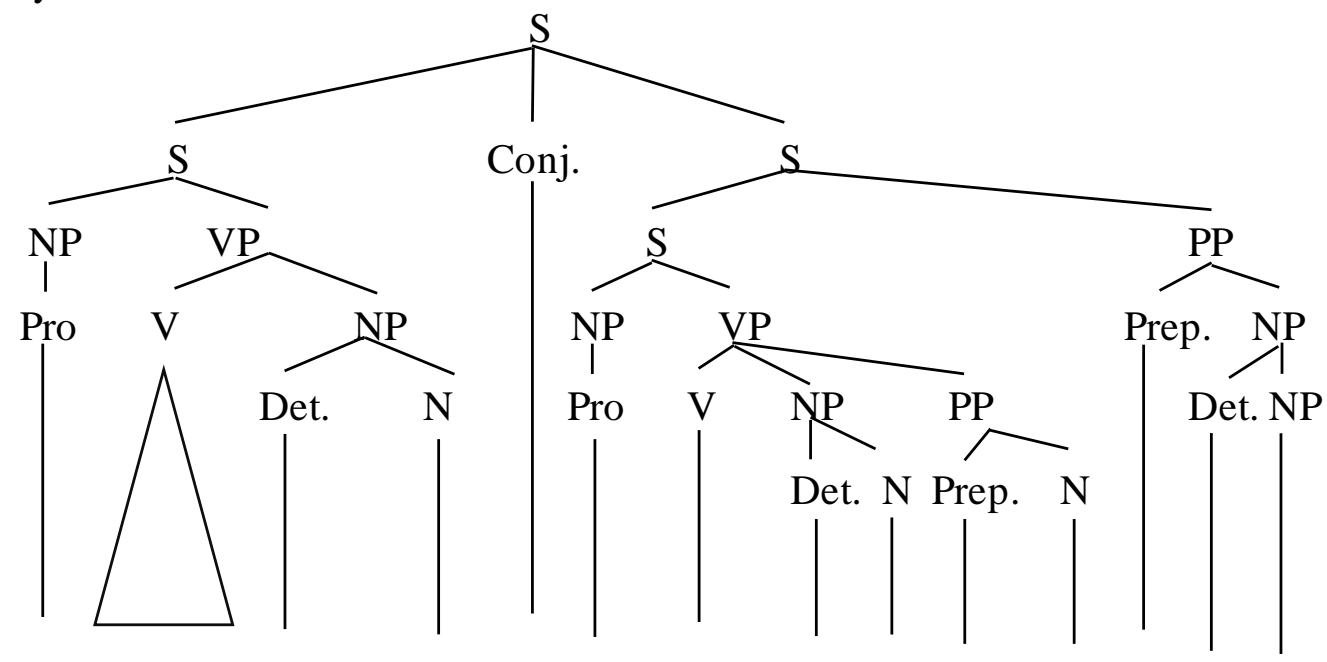

He subbed out the cigarette and (He) Shuffled a pile of papers on his desk

The type ellipsis of this sentence is ellipsis of subject (and auxiliary). The sentence has two clauses which are leftmost $S$ and rightmost $S$ then they are separated by conjunction and. Those clauses have noun phrase constituents (NP) and verb phrase constituents (VP) as the branches of S. the noun phrase (NP) constituent is $\mathrm{He}$ that the realized items is in the leftmost $\mathrm{S}$ meanwhile the constituent noun phrase (NP) in the rightmost S is empty. Therefore, this sentence is categorized as the ellipsis of subject (and auxiliary).

\subsection{ELLIPSIS OF PREDICATE OR PREDICATION}

Ellipsis of predicate or predication is the types of ellipsis if the predicate or predication is ellipted. The subject maybe ellipted as well. In this study there were 8 data found. The selected data are as follows:

Data 2: I met Watson and a detective named Constable KateCafarella at the Mona Va le Police Station

The sentence above is classified into ellipsis of predicate or predication that has two clauses and separated by conjunction and. Originally the sentence must be I met Watson and (I met) a detective named Constable Kate Cafarella at the Mona Vale Police Station; however, after being ellipted the sentence becomes I met Watson and a detective named Constable Kate Cafarella at the Mona Vale Police Station. The word $I$ as the constituent of noun phrase and met as the constituent of verb are empty in the second clause to avoid repetition. Therefore, this sentence is classified into ellipsis of predicate or predication. The constituent structure of sentence is represented below: 


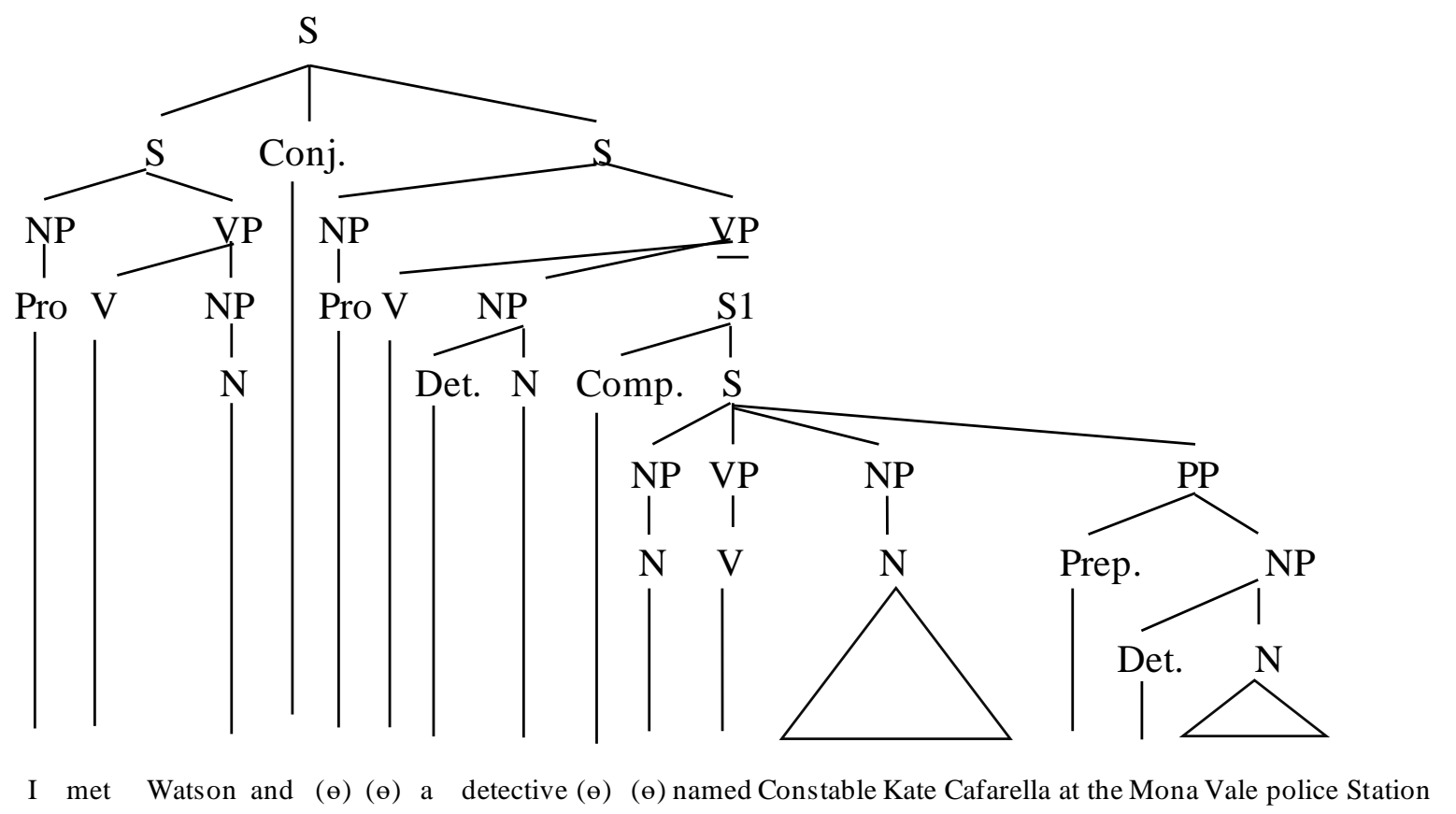

The mother nodes $\mathrm{S}$ broke into two branches which is leftmost $\mathrm{S}$ and rightmost $\mathrm{S}$. The leftmost $\mathrm{S}$ has branches which is noun phrase (NP) and verb phrase (VP). Immediate constituent noun of noun phrase is $I$ and constituent verb phrase (VP) has two branches they are verb and noun phrase, the immediate constituent verb of verb phrase is met and noun phrase is Watson then the rightmost $\mathrm{S}$ also has two branches which is noun phrase (NP) and verb phrase (VP), however because of the empty of the noun and verb therefore it is symbolized by using symbol $(\Theta)$.

\subsection{ELLIPSIS OF WHOLE OF PREDICATION}

Ellipsis of whole of predication is the predication is ellipted completely. The data found in this study is 1 data.

Data 3: I had to hope she wouldn'tmention faxes and she didn't

The sentence has two clauses that are separated by conjunction and. The ellipsis of whole of predication occur in the second clause, the real construction must be I had to hope she wouldn't mention faxes and she didn't (mention faxes). Meanwhile after being ellipted the sentence becomes I had to hope she wouldn't mention faxes and she didn't. The whole of predication of sentence is the verb ellipted and accompanied by the noun phrase. Explanation of sentence structure is portrayed below:

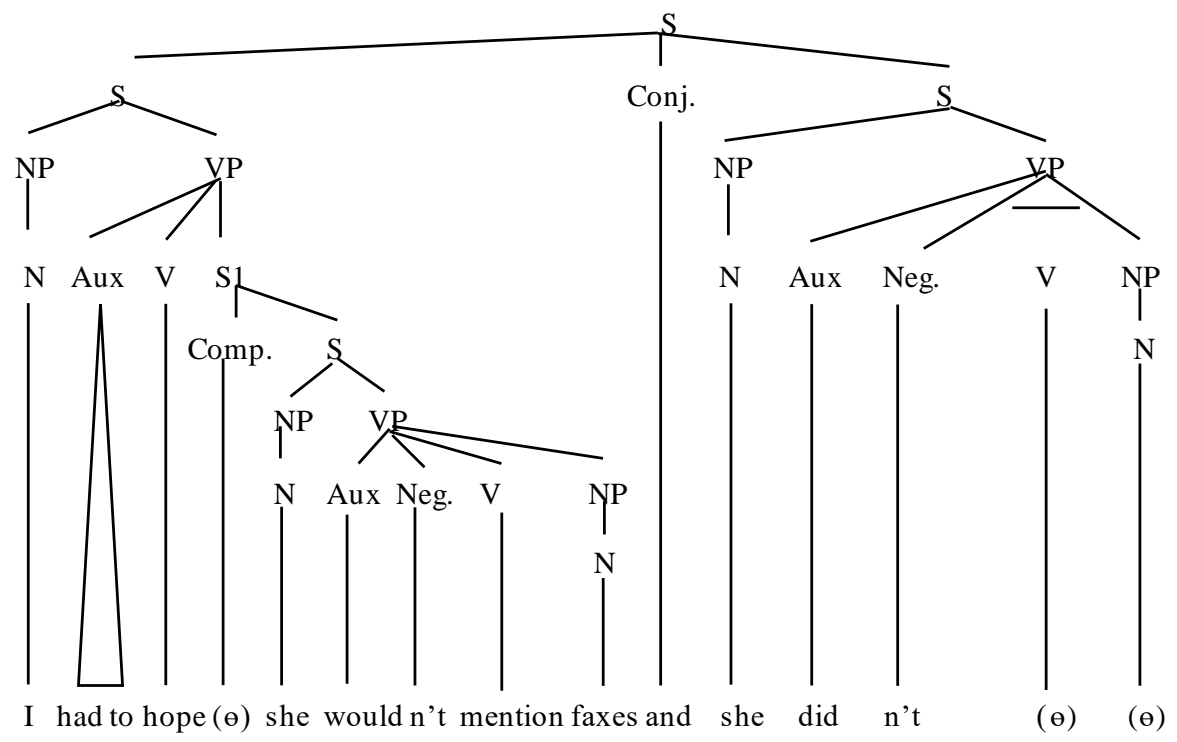

From the tree diagram above, it can be seen that the mother nodes $S$ is separated into leftmost $S$ and rightmost $\mathrm{S}$. braches of leftmost $\mathrm{S}$ is noun phrase (NP) and verb phrase (VP), immediate noun of noun phrase is $I$, then the constituent verb phrase has three branches they are auxiliary (Aux), verb (V) and S1. In the S1 there were independent clause explained she wouldn't mention faxes. Word she as the 
constituent of noun phrase, would not as the constituent of auxiliary and negative, then mention faxes as the constituent of verb and noun phrase and becomes the whole predication. Meanwhile, the rightmost $S$ is she didn't as the constituent of noun phrase and auxiliary. However, the empty of constituent verb and noun phrase is indicated by using symbol $(\theta)$. That mean the constituent is ellipted.

\subsection{ELLIPSIS OF DIRECT OBJECT OR SUBJECT COMPLEMENT}

Ellipsis of direct object or subject complement is the direct object or subject complement is ellipted. In this study there were only 1 data found.

Data 4: the bonus was useful, the publicity wasn't

The sentence above is categorized into ellipsis of direct object or subject complement because the subject complement in the second clause is ellipsis. The first sentence is the bonus was useful, while the second clause is the publicity wasn't. the subject complement of useful is ellipted alone. If the ellipsis does not occur in the sentence, the real sentence must be the bonus was useful, the publicity wasn't useful. The constituent structure of sentence can be seen as below:

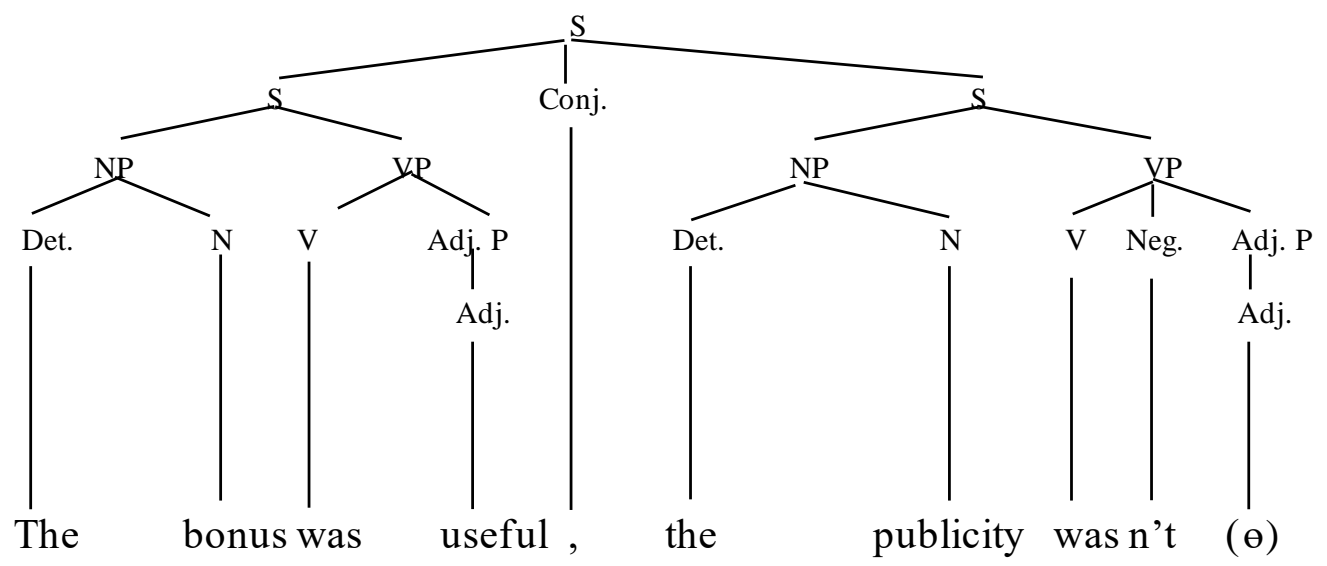

The diagram above first expanded into two branches which is leftmost $\mathrm{S}$ and rightmost $\mathrm{S}$, in the middle is sign coma (,) that separated the clause. Leftmost $\mathrm{S}$ has two branches which is noun phrase (NP) and verb phrase (VP), the bonus was useful. The bonus is the constituent of noun phrase and was useful is the constituent of verb phrase, was is constituent of verb and useful is constituent of adjective. While the publicity wasn't is the constituent of rightmost $S$, which the publicity is the constituent of noun phrase and wasn 't is the constituent of verb phrase. However, the constituent of adjective is empty and it is indicated by symbol ( $\theta)$ that means the constituent is ellipted.

\subsection{ELLIPSIS OF HEAD OF NOUN PHRASE AND PREPOSITIONAL COMPLEMENT}

Ellipsis of noun phrase and prepositional complement is the noun of noun phrase and preposition of object is ellipted. In this study only 1 data found. The representative of data can be seen below:

Data 5: I tell you some things and you do the same

The sentence above is categorized as ellipsis of head of noun phrase and prepositional complement; If the process of ellipsis does not occur in the sentence the real sentence must be I tell you some things and you do the same (things). In the second clause the head of noun phrase which is things is ellipted. Therefore, this sentence is categorized as ellipsis of head of noun phrase and prepositional complement. 


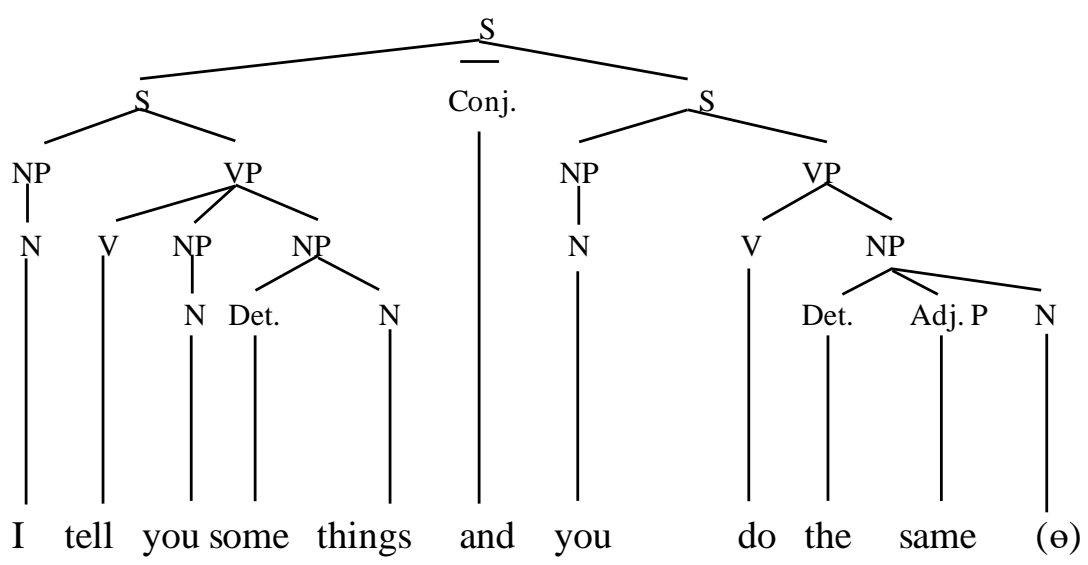

The tree diagram above shows that the mother nodes $\mathrm{S}$ is expanded into two branches which is leftmost $\mathrm{S}$ ad rightmost $\mathrm{S}$. Constituent of leftmost $\mathrm{S}$ is I tell you some things. I is the constituent of noun phrase and tell you some things is the constituent of verb phrase. The head of noun phrase is (things). You do the same is the constituent of leftmost S; you is the constituent of noun phrase and do the same is the constituent of verb phrase. However, the constituent of (things) as the head of noun phrase is empty. Therefore, it is indicated by using symbol $(\theta)$

\section{CONCLUSION}

This study analyzed types of elliptical sentence in Open File A Cliff Hardy by Peter Corris and the constituent structure of sentence. There are 200 data of elliptical sentence, the finding show s that there are five types of elliptical sentence, they are: $94,5 \%$ of ellipsis of subject (and auxiliary), $4 \%$ of ellipsis of predicate or predication, $0.5 \%$ of ellipsis of whole of predication, $0.5 \%$ of direct object or subject complement and $0.5 \%$ of head of noun phrase and prepositional complement. Ellipsis of subject (and auxiliary) is the subject alone ellipsis in the sentence to avoid the repetition of subject, ellipsis of predicate or predication is the first part of predicate or predication ellipted. ellipsis of whole of predication is the predicate ellipted and accompanied by the noun phrase or other complement, ellipsis of direct object or subject complement is the direct object alone is ellipted, and the ellipsis of head of noun phrase and prepositional complement is the noun of noun phrase and preposition of object is ellipted. Among six types of elliptical sentence, ellipsis of subject (and auxiliary) is the most dominant types of ellipsis found in this study. This type became more dominant than the other due to the fact that character use in the sentence is the same in order to avoid repetition of subject in the sentence.

\section{REFERENCES}

Keith, Brown, \& Miller. (1991). Syntax: A Linguistics Introduction to Sentence Structure. Great Britain. Harper Collins Academic.

Quirk, \& al., R. E. (1973). A Grammar of Contemporary English. london: longman.

Quirk, R., \& Greenbaum, S. (1973). A University Grammar of English

Sudaryanto. (1993). Metode dan Aneka Teknik Analisis Bahasa (Pengantar Penelitian Wahana Kebudayaan Secara Linguistics). Yogyakarta: Duta Wacana University Press. 